Article

\title{
Experimental Validation of Finite Element Models for Reinforced Concrete Beams with Discontinuities That Form Dowel-Type Joints
}

\author{
Marios Filippoupolitis ${ }^{1,2, *}$ and Carl Hopkins ${ }^{2}$ (D) \\ 1 Institute for Risk and Uncertainty, University of Liverpool, Liverpool L69 7ZF, UK \\ 2 Acoustics Research Unit, School of Architecture, University of Liverpool, Liverpool L69 7ZN, UK; \\ carl.hopkins@liverpool.ac.uk \\ * Correspondence: m.filippoupolitis@liverpool.ac.uk
}

Citation: Filippoupolitis, M.;

Hopkins, C. Experimental Validation

of Finite Element Models for

Reinforced Concrete Beams with

Discontinuities That Form

Dowel-Type Joints. Vibration 2021, 4 ,

537-550. https://doi.org/10.3390/

vibration 4030032

Academic Editor: Vitomir Racic

Received: 16 May 2021

Accepted: 2 July 2021

Published: 5 July 2021

Publisher's Note: MDPI stays neutral with regard to jurisdictional claims in published maps and institutional affiliations.

Copyright: $\odot 2021$ by the authors. Licensee MDPI, Basel, Switzerland. This article is an open access article distributed under the terms and conditions of the Creative Commons Attribution (CC BY) license (https:// creativecommons.org/licenses/by/ $4.0 /)$.

\begin{abstract}
Earthquakes have the highest rate of mortality among the natural disasters and regularly lead to collapsed structures with people trapped inside them. When a reinforced concrete building collapses due to an earthquake, many of the concrete elements (i.e., beams and columns) are damaged and there are large sections where the concrete is missing and the steel reinforcement is exposed (i.e., concrete discontinuities). The prediction of vibration transmission in collapsed and severely damaged reinforced-concrete buildings could help decisions when trying to detect trapped survivors; hence there is need for experimentally validated finite element models of damaged concrete elements. This paper investigates the dynamic behaviour of damaged reinforced concrete beams using Experimental Modal Analysis (EMA) and Finite Element Methods (FEM). FEM models are assessed using two beams with one or more concrete discontinuities that form dowel-type joints. These models used either beam or spring elements for the exposed steel bars and were experimentally validated against EMA in terms of eigenfrequencies and mode shapes. Improved agreement was achieved when using springs instead of beam elements in the FEM model. The comparison of mode shapes used the Partial Modal Vector Ratio (PMVR) as a supplement to the Modal Assurance Criterion (MAC) to confirm that spring elements provide a more accurate representation of the response on all concrete parts of the beams.
\end{abstract}

Keywords: reinforced concrete; finite element modelling; dowel-type joints

\section{Introduction}

Earthquakes have the highest rate of mortality among the natural disasters [1] and most of the casualties occur in collapsed buildings [2] where concrete elements are severely damaged and there are large sections where the concrete is missing and the steel reinforcement is exposed (e.g., see [3-5]). It is common for conscious, trapped human survivors to knock or hit the nearest part of the collapsed structure to try and inform the rescuers that they are still alive. It is critical to locate survivors within a short period of time (i.e., $72 \mathrm{~h}$ ) to increase their chance of survival [6]. Some rescue teams have limited experience in distinguishing human induced vibrations from other sources of vibration to assess when other search and rescue activities (e.g., digging) should stop in order to listen for signs of life $[7,8]$. The ability to predict vibration transmission in collapsed and severely damaged reinforced-concrete buildings could aid decision making when searching for trapped survivors. Previous work by Filippoupolitis and Hopkins [9] investigated the potential to predict vibration transmission across unbonded contacts between concrete beams in collapsed buildings. This used experimentally validated finite element models of beams junctions at frequencies up to a few kilohertz. However, for junctions of beams with and without concrete discontinuities it was found that the use of beam elements for modelling the steel reinforcement was less effective where the reinforcement was exposed and the steel bars were behaving as dowels. 
This paper investigates two different approaches using Finite Element Methods (FEM) to model the dynamic behaviour of beams with concrete discontinuities. These models are validated with new experimental data on a concrete beam with two discontinuities along with previous data [9] from a beam with one discontinuity. Although finite element models of these 'dowel-type' joints have been investigated in other areas of engineering in terms of statics, failure and cracks (e.g., see [10-13]), there does not appear to have been similar published work providing experimentally validated models for their dynamic response. In addition, the experimental validation includes larger numbers of bending and torsional modes than are commonly used to validate FEM for damage detection (e.g., see $[14,15]$ ) because the upper frequency of interest to use vibration to detect survivors within a collapsed building will potentially need to consider many more modes at frequencies up to a few kilohertz.

FEM modelling of reinforced concrete beams usually combines solid elements for the concrete and truss elements (e.g., see [16-19]) or beam elements [17] for the reinforcement. Truss elements have one degree of freedom per node and can support axial deformation but not bending wave motion [20]. For this reason, they are not appropriate for modelling the steel reinforcement in the damaged sections of a beam. Beam elements can model bending wave motion and therefore they could be adopted for modelling the exposed steel reinforcement. A 'smeared approach' to the modelling of reinforced concrete [18] considers the steel reinforcement by using solid elements with equivalent properties calculated as weighted averages of the properties of reinforcement and concrete. For this reason, it is not appropriate for modelling beams with discontinuities where the exposed reinforcement bars can act as dowels [10,11]. The action of a dowel bar can be simplified in FEM by using springs. For example, Chung et al. [12] investigated dowel joints with floating slabs used for railway tracks with springs to model the action of a dowel bar between adjacent slabs.

This paper focuses on the validation of FEM models for bending and torsional motion of reinforced concrete beams where there are discontinuities in the concrete with dowel-type joints due to the steel reinforcement. An improved model is developed using linear elastic springs for the exposed reinforcement bars for comparison with previous models using beam elements. Both models are compared against Experimental Modal Analysis (EMA) in terms of eigenfrequencies and mode shapes. The latter requires use of the Partial Modal Vector Ratio (PMVR) [9] because the Modal Assurance Criterion (MAC) is not sufficient to identify the correct response on parts of the beam which have a relatively low response.

\section{Experimental Work}

\subsection{Test Specimens}

The test specimens consist of two reinforced concrete beams $(2400 \mathrm{~mm} \times 200 \mathrm{~mm} \times$ $300 \mathrm{~mm}$ ). Eight steel bars of $16 \mathrm{~mm}$ diameter were used for the longitudinal reinforcement whilst the transverse reinforcement consists of $8 \mathrm{~mm}$ diameter stirrups placed at $200 \mathrm{~mm}$ centres along the beams (see Figure 1). To simulate idealized fractures that could occur in a collapsed building, Beam 1 and Beam 2 were designed to have one and two discontinuities that were $100 \mathrm{~mm}$ wide, respectively.

\subsection{Material Properties}

Table 1 shows the material properties of the beams. The density of the concrete for each beam was calculated by dividing the measured weight of the beams by the volume of concrete after extracting the weight of the steel reinforcement. The Young's modulus of the concrete was estimated through updating the FEM model [9]. Material properties for steel and Poisson's ratio for concrete were taken from published data [21,22].

\subsection{Test Setups}

Each beam was suspended from a crane using polyester slings (see Figure 2). For the experimental work and the FEM models, the slings were assumed to have negligible effect on the dynamic response such that the beams can be assumed to have free-free boundary conditions. 

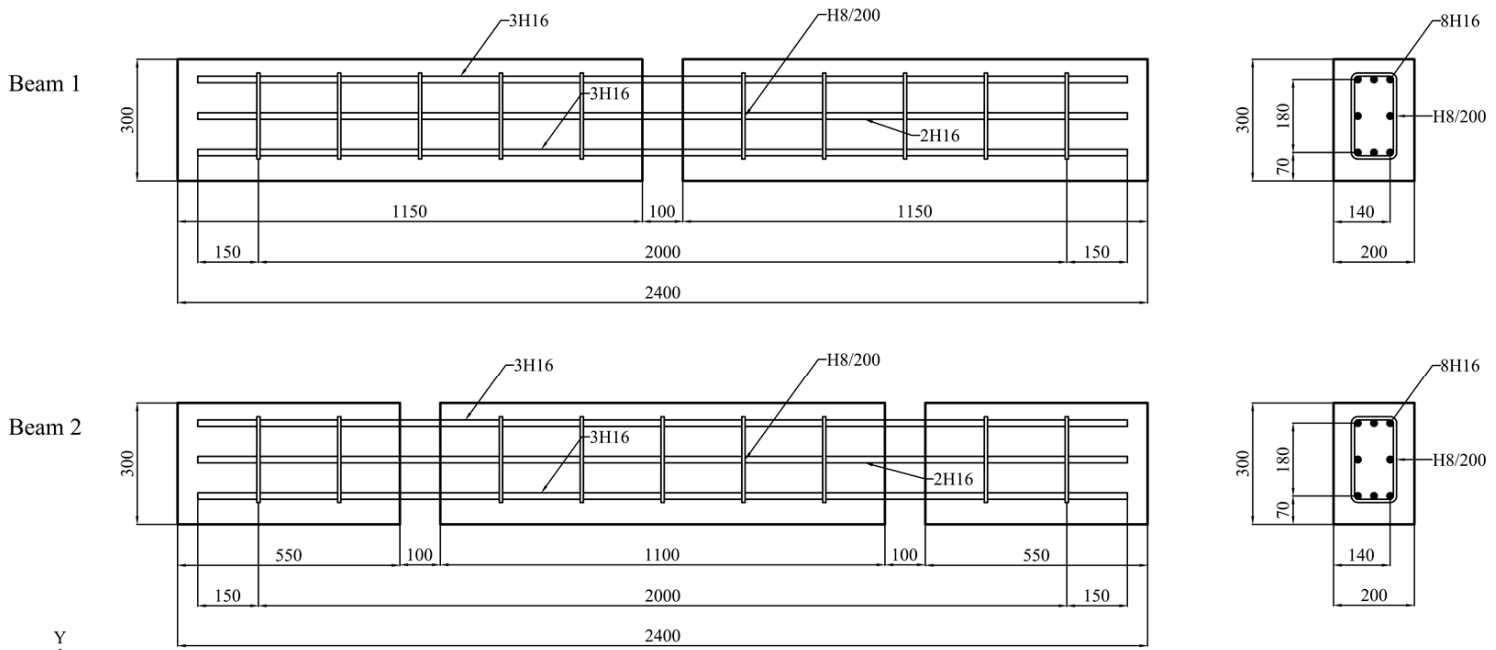

Figure 1. Dimensions of reinforced concrete Beam 1 and Beam 2 (mm).

Table 1. Material properties of the concrete and steel used for Beam 1 and Beam 2.

\begin{tabular}{|c|c|c|c|c|}
\hline \multirow{2}{*}{$\begin{array}{l}\text { Material } \\
\text { Concrete } \\
(\mathrm{C} 25 / 30)\end{array}$} & \multicolumn{2}{|c|}{ Density, $\rho\left(\mathrm{kg} / \mathrm{m}^{3}\right)$} & \multirow{2}{*}{$\begin{array}{c}\text { Young's Modulus, E }\left(\mathbf{N} / \mathbf{m}^{\mathbf{2}}\right) \\
3.2475 \times 10^{10}\end{array}$} & \multirow{2}{*}{$\begin{array}{c}\text { Poisson's Ratio, } \boldsymbol{v}(-) \\
0.2\end{array}$} \\
\hline & $\begin{array}{l}\text { Beam } 1 \\
\text { Beam } 2\end{array}$ & $\begin{array}{l}2235 \\
2234\end{array}$ & & \\
\hline Steel (S500) & \multicolumn{2}{|c|}{7800} & $2 \times 10^{11}$ & 0.3 \\
\hline
\end{tabular}
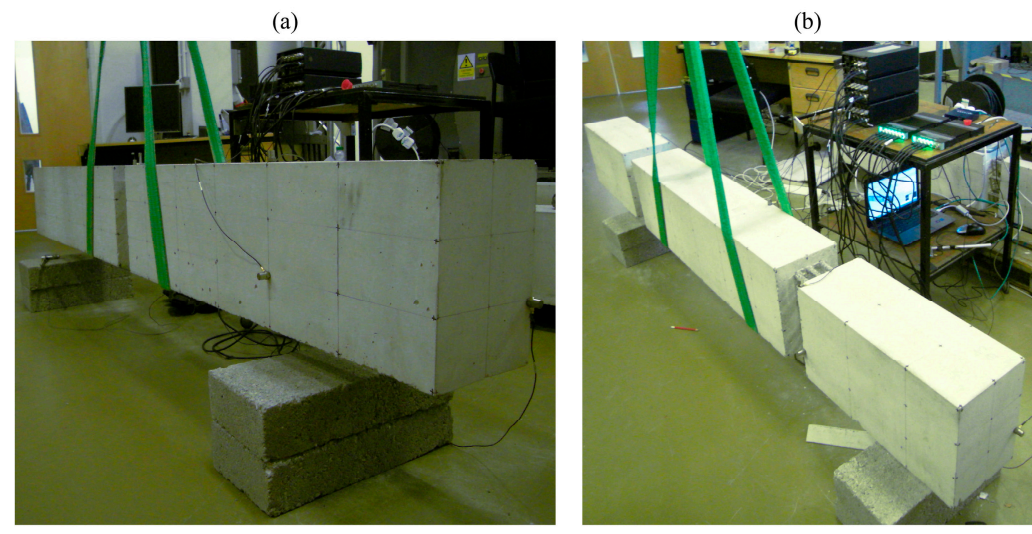

Figure 2. Test setup showing the test equipment and the polyester slings that approximate the free-free boundary conditions: (a) Beam 1; (b) Beam 2.

\subsection{Modal Analysis}

EMA is used to identify the modal characteristics of these two beams using FFT analysis with $3200 \mathrm{FFT}$ lines and $1 \mathrm{~Hz}$ frequency resolution. The frequency span was $3200 \mathrm{~Hz}$ and the record length was 1 s. Pulse Reflex software (Version 20, Brüel \& Kjær, Nærum, Denmark) was used for signal processing and to carry out EMA. The beams were excited using an impact hammer (Brüel \& Kjær Type 8200) and the response was measured using accelerometers (Brüel \& Kjær Type 4371), both connected to a Nexus conditioning amplifier (Brüel \& Kjær Type 2692) and a channel input module (Brüel \& Kjær Type 3050-A060). Table 2 show the number of accelerometers and the number of the excitation positions for each setup whilst Figure 3 shows the layout of the measuring positions. The Rational Fraction Polynomial- $Z$ method was used to estimate the modal parameters (i.e., modal 
damping, frequency and complex mode shapes) from the generated Frequency Response Functions (FRF).

Table 2. Accelerometers and excitation positions for each test setup. In plane transducers excite/measure the response in the $\mathrm{X}$ and $\mathrm{Z}$-directions. Out-of-plane transducers excite/measure the response in the Y-direction.

\begin{tabular}{ccccc}
\hline \multirow{2}{*}{ Beam } & \multicolumn{2}{c}{ No. of Accelerometers } & \multicolumn{2}{c}{ No. of Excitation Positions } \\
\cline { 2 - 5 } & In-Plane & Out-of-Plane & In-Plane & Out-of-Plane \\
\hline 1 & 4 & 2 & 160 & 84 \\
2 & 6 & 3 & 192 & 90 \\
\hline
\end{tabular}

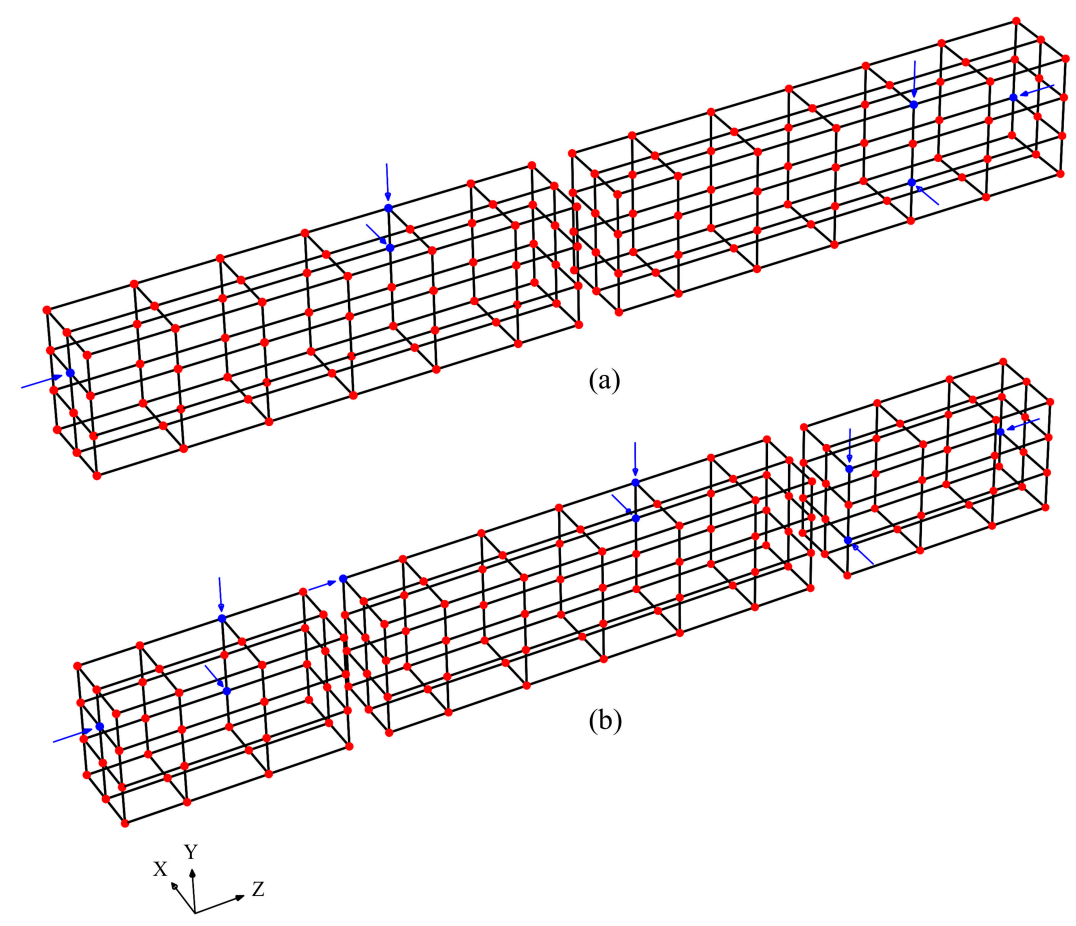

Figure 3. EMA measuring positions: (a) Beam 1; (b) Beam 2. The blue and red markers indicate the accelerometers and excitation positions respectively whilst the blue arrows show the measuring direction of each accelerometer.

\section{FEM Modelling}

All finite element models used Abaqus software (Version 6.14, Dassault Systemes, Paris, France) [23]. Eigenvalue extraction used the Lanczos solver in the frequency range from $1 \mathrm{~Hz}$ to $3.2 \mathrm{kHz}$. The extracted mode shapes were real valued.

\subsection{Reinforced Concrete Beams with Dowel-Type Joints}

The concrete and the steel bars were modelled using solid element C3D20R (20 nodes) and beam element B32 ( 3 nodes) respectively. Both elements were selected to have interpolation functions of the same order (quadratic) to avoid a reduction in accuracy [23]. The element mesh had dimensions of $25 \mathrm{~mm}$ along the length of the beam and $10 \mathrm{~mm}$ over the beam cross-section to fulfil the requirement of at least six elements per bending wavelength [24] at frequencies up to $3200 \mathrm{~Hz}$.

Two different FEM models were used for the exposed steel at the discontinuities. In FEM model No.1, the steel bars were modelled using the Abaqus beam element B32. In FEM model No.2, three Abaqus SPRING2 elements [23] without dashpots were introduced in the three-coordinate directions to model the action of the steel bars between adjacent 
reinforced concrete blocks (see Figure 4). Beam elements have six degrees of freedom (DOF) per node (three translational and three rotational) whilst spring and solid elements have one and three translational DOF per node respectively; hence the elements were connected only via the translational DOF.

(a)

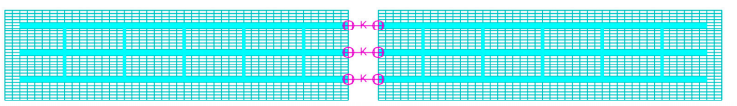

Side view

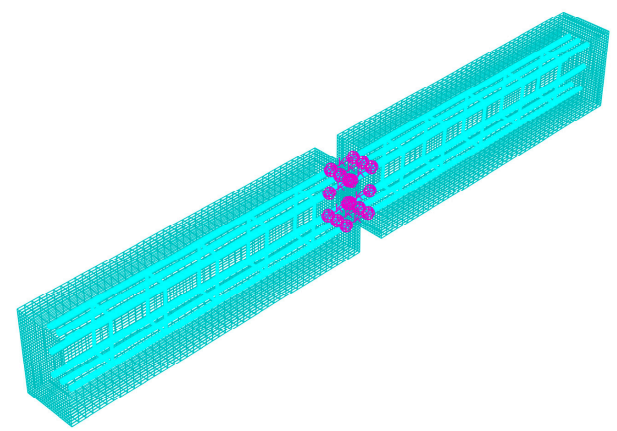

(b)
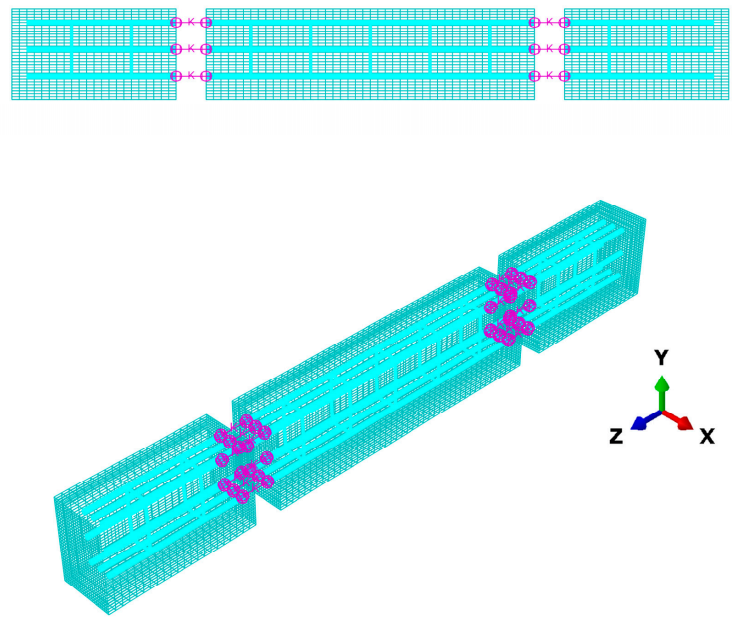

Isometric vicw

Figure 4. FEM model No.2: (a) Beam 1; (b) Beam 2. Purple circular markers indicate the SPRING2 elements that are used to model the steel bars at the discontinuities in the concrete.

The axial spring stiffness, $k_{\mathrm{z}}(\mathrm{N} / \mathrm{mm})$ for each steel bar is given by [20],

$$
k_{z}=A_{\mathrm{s}} E_{\mathrm{s}} / L
$$

where $A_{\mathrm{s}}$ is the cross-sectional area of a steel bar $\left(\mathrm{mm}^{2}\right), E_{\mathrm{s}}$ is the Young's modulus of steel $\left(\mathrm{N} / \mathrm{mm}^{2}\right)$ and $L$ is the width of the discontinuity $(\mathrm{mm})$.

The relative displacement of the steel bars at the discontinuities can be decomposed into components representing displacements from the embedded and the exposed region of the bars $[12,25]$. This gives the transverse spring stiffness, $k_{x}$ and $k_{y}(\mathrm{~N} / \mathrm{mm})$ as,

$$
k_{x}=k_{y}=\left(\frac{2}{k_{\mathrm{d}}}+\frac{L^{3}}{12 E_{\mathrm{s}} I_{\mathrm{s}}}+\frac{\lambda L}{A_{\mathrm{s}} G_{\mathrm{s}}}\right)^{-1}
$$

where $I_{\mathrm{S}}$ is the moment of inertia of a steel bar $\left(\mathrm{mm}^{4}\right), \lambda$ is the shear shape factor (equal to $10 / 9$ for circular cross sections [25]) and $G_{\mathrm{S}}$ is the shear modulus of steel $\left(\mathrm{N} / \mathrm{mm}^{2}\right)$.

The second and third terms in the brackets of Equation (2) correspond to the bending and shear stiffness, respectively, of the exposed region of the steel bars. The stiffness from the embedded region of the bars is represented by the dowel stiffness, $k_{\mathrm{d}}$, which is given by [12],

$$
k_{\mathrm{d}}=\beta^{3} E_{\mathrm{s}} I_{\mathrm{s}}
$$

where $\beta=\left[d_{\mathrm{s}} K_{\mathrm{b}} / 4 E_{\mathrm{s}} I_{\mathrm{s}}\right]^{0.25}, d_{\mathrm{s}}$ is the steel bar diameter $(\mathrm{mm})$ and $k_{\mathrm{b}}$ is the concrete bearing stiffness (foundation modulus) given by the empirical equation of Soroushian et al. [26],

$$
k_{\mathrm{b}}=\frac{127 c_{\mathrm{f}} \sqrt{f_{\mathrm{c}}}}{d_{\mathrm{s}}^{2 / 3}}
$$

where $f_{\mathrm{c}}$ is the compressive strength of concrete $\left(\mathrm{N} / \mathrm{mm}^{2}\right)$ and $c_{\mathrm{f}}$ is a coefficient from Soroushian et al. that ranges from 0.6 for a clear bar spacing of $25.4 \mathrm{~mm}$ to 1.0 for "large bar spacings". 
The smallest and largest clear bar spacings tested by Soroushian et al. [26] were $25.4 \mathrm{~mm}$ and $101.6 \mathrm{~mm}$ respectively. However, their paper gave no information on intermediate spacings because they only used these two spacings in series IV of their tests. In this paper, the clear spacing, $w$ of the reinforcement bars is 24 and $74 \mathrm{~mm}$ in the $X$ and Y-directions, respectively, (see Figure 5). It is assumed that (a) the value of $c_{\mathrm{f}}=0.6$ which came from Soroushian et al. for a spacing of $24 \mathrm{~mm}$ is also a reasonable estimate for a spacing of $25.4 \mathrm{~mm}$ and $(\mathrm{b})$ that $c_{\mathrm{f}}=1.0$ applies to a spacing of $101.6 \mathrm{~mm}$. Hence by using linear interpolation, a value of $c_{\mathrm{f}}=0.85$ can be found for a spacing of $74 \mathrm{~mm}$. Averaging the two $c_{\mathrm{f}}$ values for 24 and $74 \mathrm{~mm}$ spacings gives $c_{\mathrm{f}}=0.725$. Use of an average value for $c_{\mathrm{f}}$ is a pragmatic solution to calculate a single stiffness; hence to check whether use of an average value is appropriate and to assess the sensitivity of the coefficient, $c_{\mathrm{f}}$, a comparison is made between eigenfrequencies from experiments and FEM model No.2 for three combinations of $c_{\mathrm{f}}$ values (see Table 3). The default combination $\mathrm{A}$ is the average value for the $X$ - and $Y$-directions and the other two combinations use the minimum $c_{\mathrm{f}}$ value of 0.6 or the maximum value of $c_{\mathrm{f}}$ in the $\mathrm{X}$-direction and the minimum in the Y-direction.

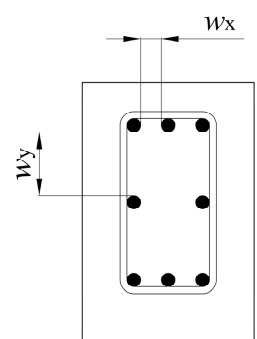

Figure 5. Cross-section of the beams indicating the clear spacings, $w_{\mathrm{x}}$ and $w_{\mathrm{y}}$, of the reinforcement bars in the $\mathrm{X}$ - and Y-directions, respectively.

Table 3. Combinations of coefficient $c_{\mathrm{f}}$ used in sensitivity analysis.

\begin{tabular}{ccc}
\hline \multirow{2}{*}{ Combination } & \multicolumn{2}{c}{$c_{\mathrm{f}}(-)$} \\
\cline { 2 - 3 } & X-Direction & Y-Direction \\
\hline A (average) & 0.725 & 0.725 \\
B & 0.6 & 0.6 \\
C & 1.0 & 0.6 \\
\hline
\end{tabular}

\subsection{Validation Criteria}

The Modal Assurance Criterion (MAC) is used to assess the correlation between bending and torsional mode shapes from FEM and EMA using [27]

$$
\operatorname{MAC}(A, X)=\frac{\left|\left\{\varphi_{X}\right\}^{\mathrm{T}}\left\{\varphi_{A}\right\}^{*}\right|^{2}}{\left(\left\{\varphi_{X}\right\}^{\mathrm{T}}\left\{\varphi_{X}\right\}^{*}\right)\left(\left\{\varphi_{A}\right\}^{\mathrm{T}}\left\{\varphi_{A}\right\}^{*}\right)}
$$

where $X$ indicates the experiment, $A$ indicates FEM, $\left\{\varphi_{X}\right\}$ and $\left\{\varphi_{A}\right\}$ are the column vectors of the degrees of freedom for the experimental and FEM mode shapes, respectively, superscript $\mathrm{T}$ indicates the transpose and ${ }^{*}$ is the complex conjugate.

MAC describes the correlation between the mode shapes. However, it does not consider the relative motion between different parts of a FEM model and is primarily determined by parts with the largest motion. This is important for the beams that are considered in this paper because the discontinuities define two (Beam 1) or three (Beam 2) sections of concrete that can have significantly different magnitude in their modal response. To overcome this limitation of MAC, the authors previously introduced the Partial Modal Vector Ratio (PMVR) [9]. This is used here to assess which FEM model more accurately models the motion of the entire beam. PMVR is defined as the ratio in decibels of the 
squared modal vectors from EMA relative to FEM for two subsets of the complete modal vector $i$ and $j$; PMVR is given by [9],

$$
\operatorname{PMVR}(A, X)_{i, j}=\left|10 \log _{10}\left(\left(\frac{\left\langle\left|\left\{\varphi_{X}\right\}_{i}\right|^{2}\right\rangle}{\left\langle\left|\left\{\varphi_{X}\right\}_{j}\right|^{2}\right\rangle}\right) /\left(\frac{\left\langle\left|\left\{\varphi_{A}\right\}_{i}\right|^{2}\right\rangle}{\left\langle\left|\left\{\varphi_{A}\right\}_{j}\right|^{2}\right\rangle}\right)\right)\right|
$$

where $\left\{\varphi_{A}\right\}$ and $\left\{\varphi_{X}\right\}$ are subsets of the modal vectors from FEM and EMA, respectively. The use of squared modal vectors ensures that PMVR considers modal energy. In this paper, a subset is defined as the vector containing the degrees of freedom for the section of concrete that is connected only via the exposed steel reinforcement (see Figure 6). Close agreement is defined as $P M V R \leq 5 \mathrm{~dB}$ and reasonable agreement as $5 \mathrm{~dB}<P M V R \leq 10 \mathrm{~dB}$ [9].

(a)

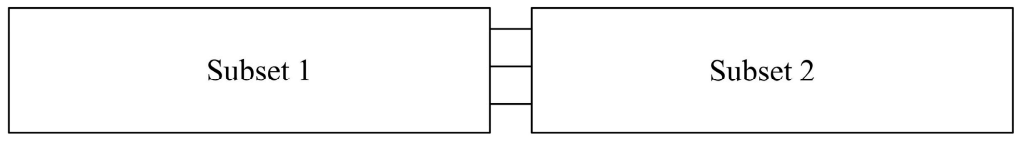

(b)

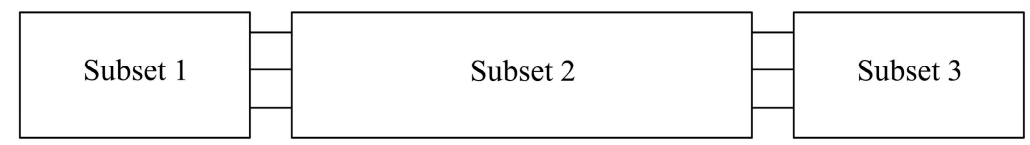

Figure 6. PMVR subsets: (a) Beam 1; (b) Beam 2.

\section{Results and Discussion}

\subsection{Eigenfrequencies}

Figure 7a,b allows comparison of FEM and EMA eigenfrequencies for Beam 1 and Beam 2 , respectively, with Figure $8 \mathrm{a}$, b showing the percentage difference $\left(\left(f_{\mathrm{EMA}}-f_{\mathrm{FEM}}\right) / f_{\mathrm{EMA}} \times\right.$ $100 \%$ ) between these eigenfrequencies. Results are shown for FEM models No.1 and 2 where model No. 2 uses combination A for the $c_{\mathrm{f}}$ values. Figure 7 shows that both FEM models are in reasonable agreement with experimental data over the first 25 mode pairs. However, Figure 8 indicates that the errors are larger at the lower frequencies. Hence, by the low-frequency range can be defined as where the percentage differences are $>5 \%$ and the high-frequency range where differences are $\leq 5 \%$. For Beam 1 in the low-frequency range (i.e., mode pairs 1 to 5), $80 \%$ of the differences are lower with FEM model No.2 compared to No.1. For Beam 2 in the low-frequency range (i.e., mode pairs 1 to 8 ), $62.5 \%$ of the differences are lower with FEM model No.2 compared to No.1. In the high-frequency range for Beam 1 (i.e., mode pairs 6 to 25), neither FEM model has an advantage but $82.4 \%$ of the differences for Beam 2 (i.e., mode pairs 9 to 25) are lower with FEM model No.2 compared to No.1. These findings indicate that FEM model No.2 is more accurate than No.1 for the prediction of eigenfrequencies.

\subsection{Mode Shapes}

After eigenmode extraction with the FEM models it is possible to classify two different types of modes of the beams by using the ratio (in decibels) of the spatial-average squared modal vectors from FEM subsets. Type A modes (see examples in Figure 9a,c) can be defined as when all subsets of the modal vector have a similar response (i.e., a ratio $\leq 15 \mathrm{~dB}$ ) whereas type $\mathrm{B}$ modes (see examples in Figure $9 \mathrm{~b}, \mathrm{~d}$ ) can be defined by the response of one or more subsets of the modal vector being significantly larger than the other subsets (i.e., a ratio $>15 \mathrm{~dB}$ ). Note that the displacements in the FEM mode shapes are more pronounced than those from EMA although they both show the same trends. This classification identified all 25 mode pairs for Beam 1 as being type A. However, Beam 2 had 11 type A modes and 14 type B modes. MAC is sensitive to large values and insensitive to 
small values in the modal vector [28]; hence it is expected to be suited to the assessment of type A modes, with type B modes potentially requiring PMVR to make a correct assessment of the FEM model.

MAC values for Beam 1 are shown in Figure 10 and the results are similar for FEM models No. 1 and 2. For the first five mode pairs where the percentage differences that were $>5 \%$ between FEM and EMA eigenfrequencies defined the low-frequency range in Section 4.1, it is seen that $M A C \geq 0.97$. In the high-frequency range where differences were $\leq 5 \%$ it was found that there was significantly lower correlation (on average), with the range being $0.45 \leq M A C \leq 1.0$. PMVR is shown in Figure 11, which indicates that close or reasonable agreement was achieved for $48 \%$ and $80 \%$ of the mode pairs from models No.1 and 2, respectively. Note that modes with $P M V R>10 \mathrm{~dB}$ had $M A C<0.8$, indicating that MAC can identify potential issues with Type A modes.
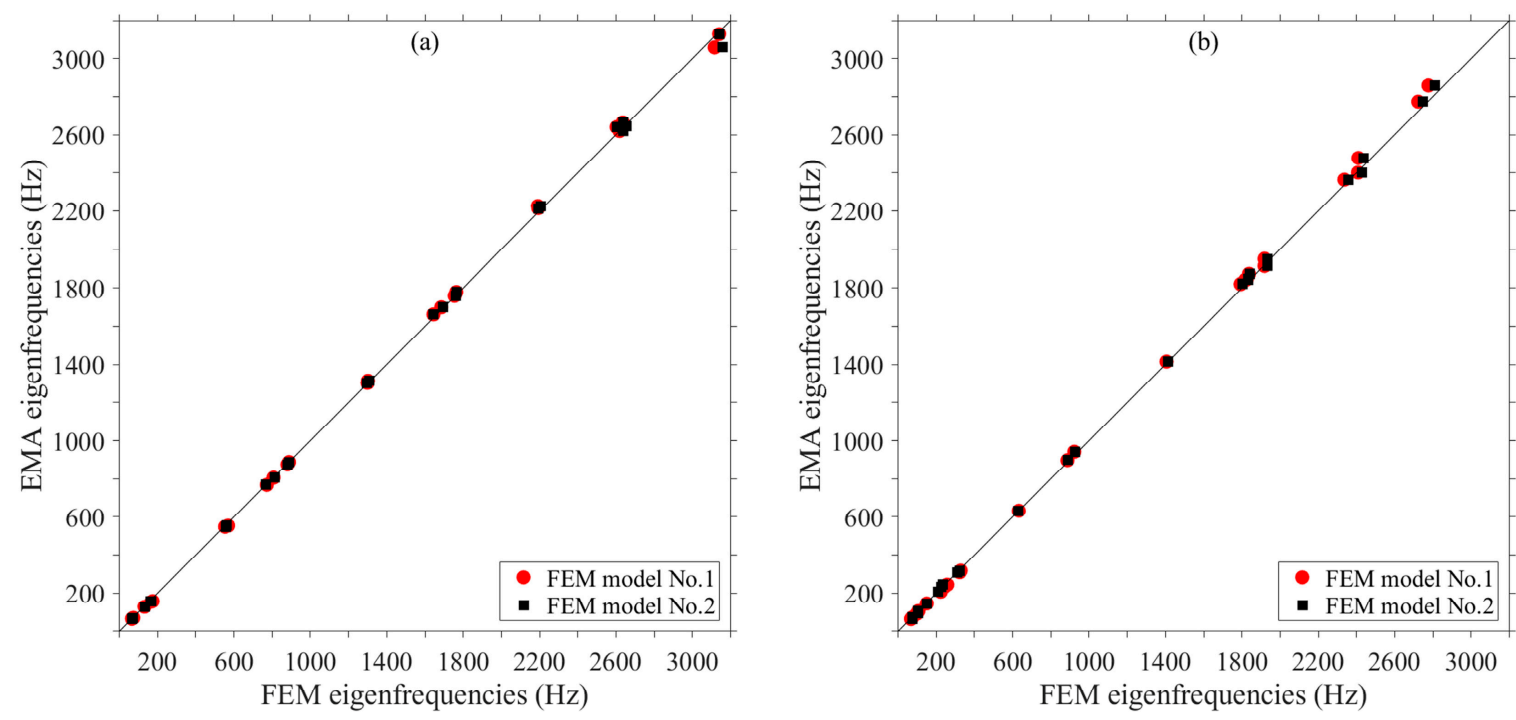

Figure 7. Comparison of FEM models No.1 and 2 against experimental (EMA) eigenfrequencies: (a) Beam 1; (b) Beam 2.

MAC values for Beam 2 are shown in Figure 12. For the first eight mode pairs where the percentage differences in eigenfrequencies $>5 \%$ defined the low-frequency range in Section 4.1, the range of MAC values were $0.8 \leq M A C \leq 0.98$ for FEM model No.1, and $0.44 \leq M A C \leq 0.98$ for FEM model No.2. However, in the high-frequency range where differences were $\leq 5 \%$ it was found that there was significantly lower correlation on average, with the range being $0.4 \leq M A C \leq 1.0$ for FEM model No.1 and No.2. For Beam 2 there are three PMVR values to consider, these are $P M V R_{12}, P M V R_{13}$, and $P M V R_{23}$ (shown in Figure 13) for which the average number of mode pairs with close agreement $(\leq 5 \mathrm{~dB})$ was $71 \%$ and $79 \%$ for FEM models No.1 and 2, respectively. While FEM model No.1 had higher MAC values than No.2, PMVR indicates that the latter provides more accurate representation of the response on all parts of the beam. Beam 2 has 14 type B modes and three of these mode pairs $(2,17$ and 24) had $M A C>0.9$, from which it could be inferred that there was high correlation, however, potential problems with these three modes are highlighted by the fact that $P M V R>10 \mathrm{~dB}$. As noted above, the reason for this is the sensitivity of MAC to large values in the modal vector. For example, in Figure $9 b$ the modal vectors of subsets 1 and 3 determine the MAC value of mode pair 17, whereas in Figure 9d the MAC value of mode pair 24 is determined by the modal vectors of subset 2.

Considering the accuracy of the predicted mode shapes using both MAC and PMVR, it is seen that FEM models No.1 and 2 are both reasonable, but that No. 2 can give slightly better agreement. 

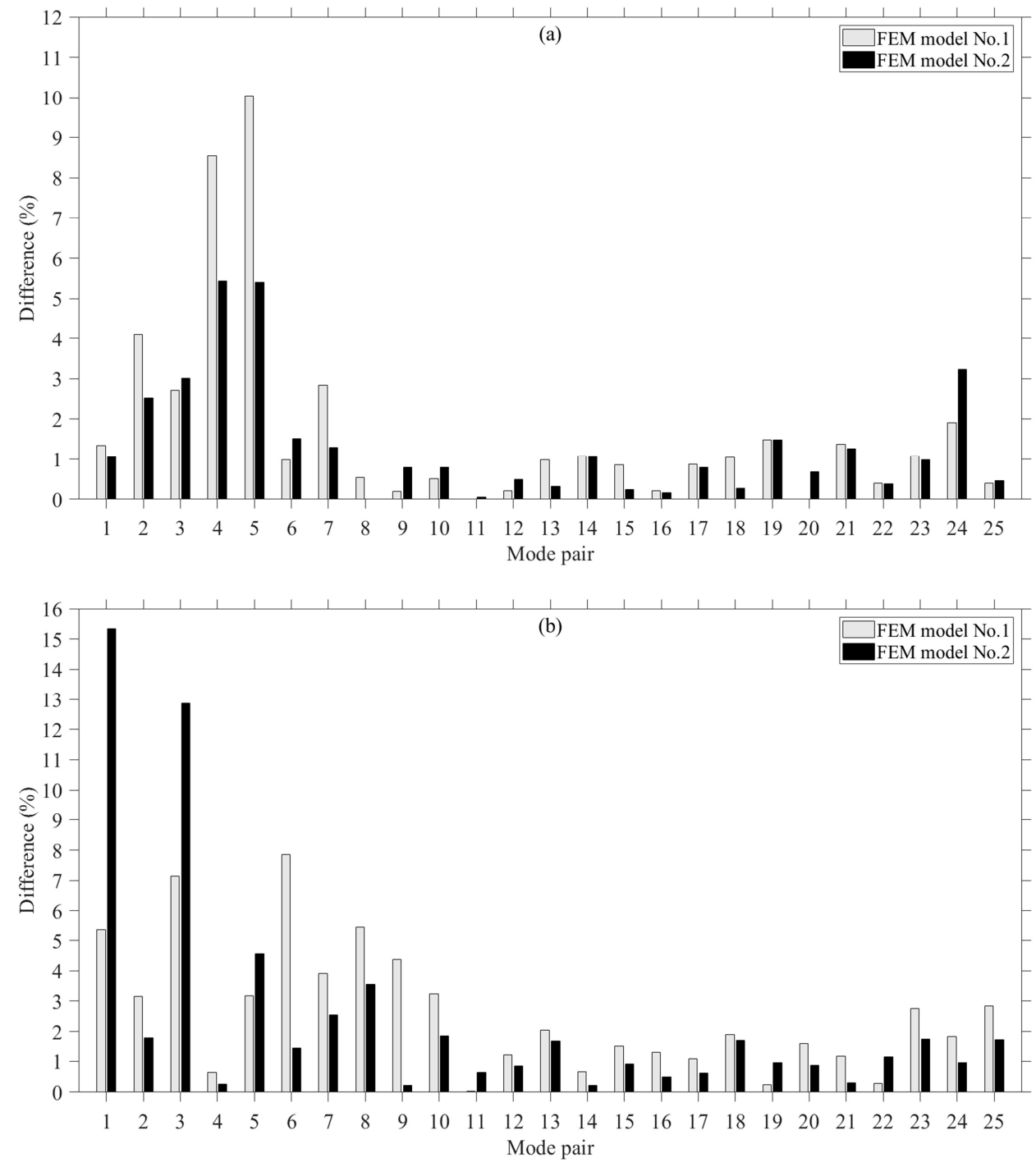

Figure 8. Percentage difference between FEM and experimental (EMA) eigenfrequencies for FEM models No.1 and 2: (a) Beam 1; (b) Beam 2.

(a)
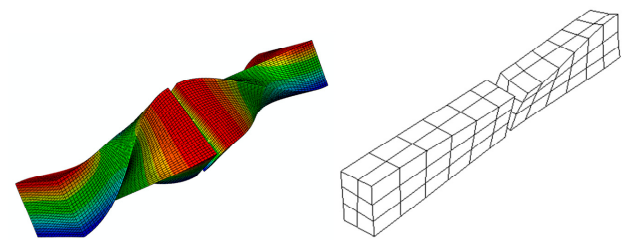

(c)
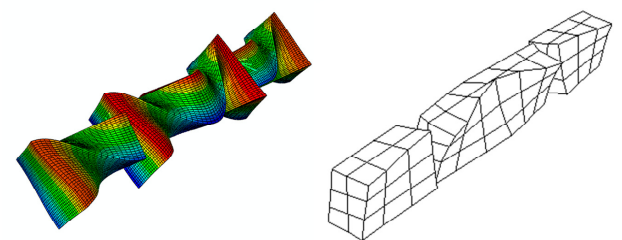

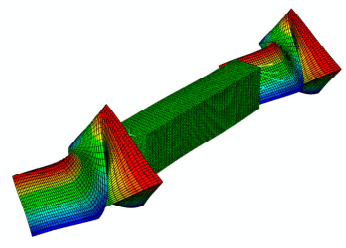

(b)

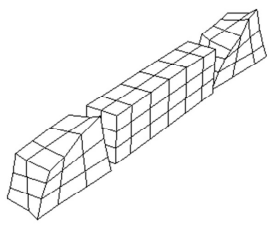

(d)
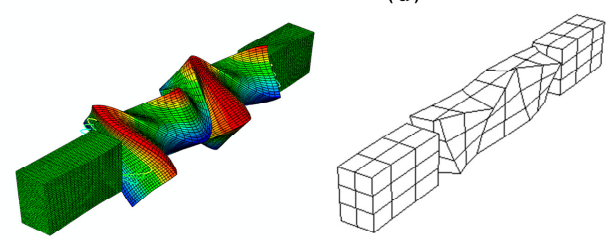

Figure 9. FEM and EMA mode shapes for model No.1: (a) Mode 10 at $875.5 \mathrm{~Hz}$ (Beam 1); (b) Mode 17 at $1845.9 \mathrm{~Hz}$ (Beam 2); (c) Mode 18 at $1872.5 \mathrm{~Hz}$ (Beam 2); (d) Mode 24 at $2773.5 \mathrm{~Hz}$ (Beam 2). 


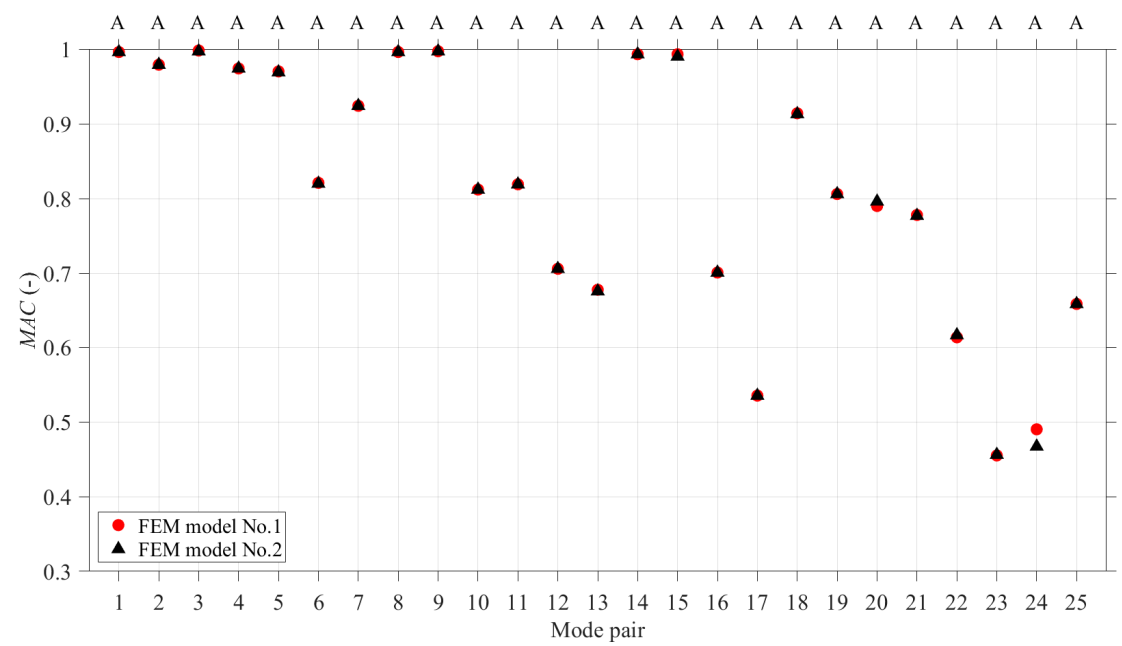

Figure 10. MAC values for FEM models No.1 and 2 of Beam 1. Mode type A or B for each mode pair is indicated on the upper $\mathrm{x}$-axis.

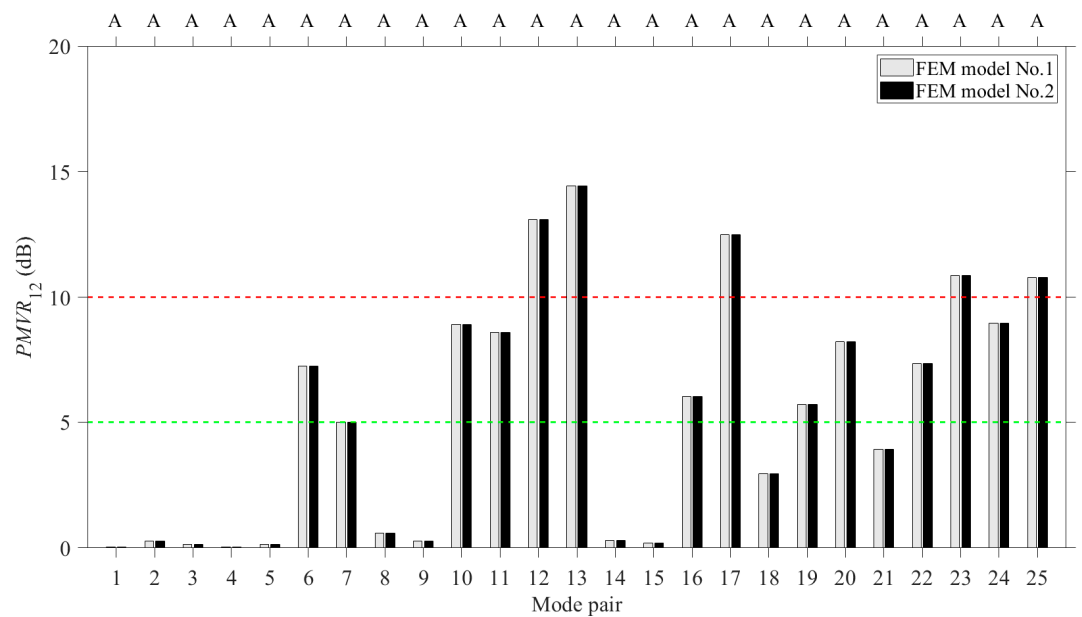

Figure 11. PMVR values for FEM models No.1 and 2 of Beam 1. Green and red lines indicate levels of $5 \mathrm{~dB}$ and $10 \mathrm{~dB}$, respectively. Mode type A or B for each mode pair is indicated on the upper x-axis.

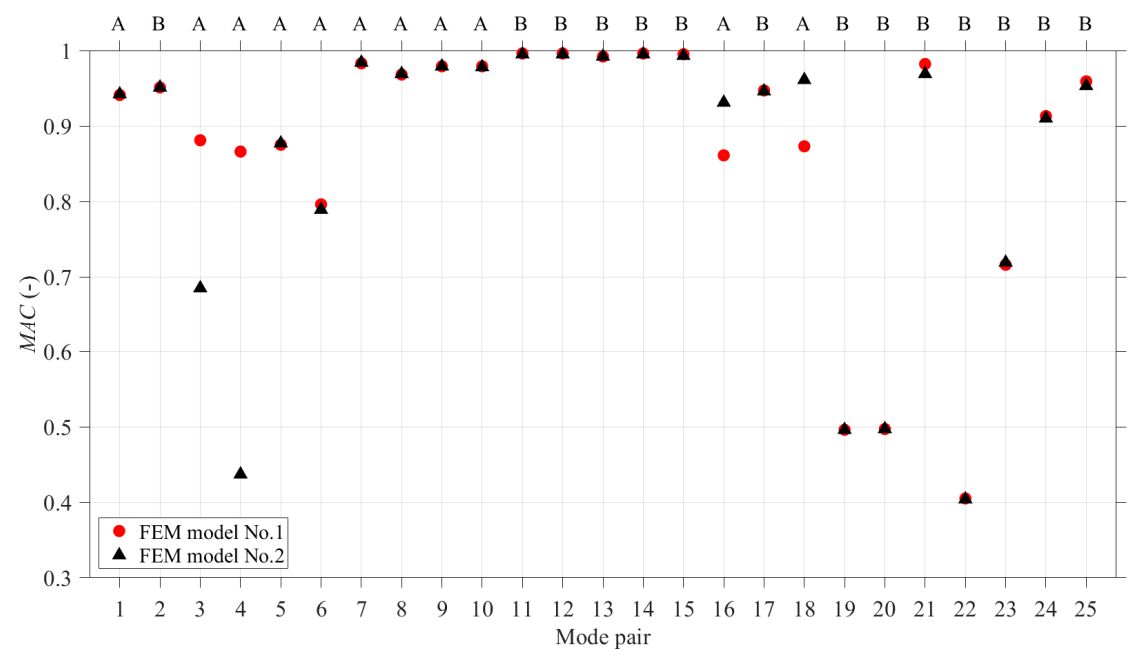

Figure 12. MAC values for FEM models No.1 and 2 of Beam 2. Mode type A or B for each mode pair is indicated on the upper $\mathrm{x}$-axis. 

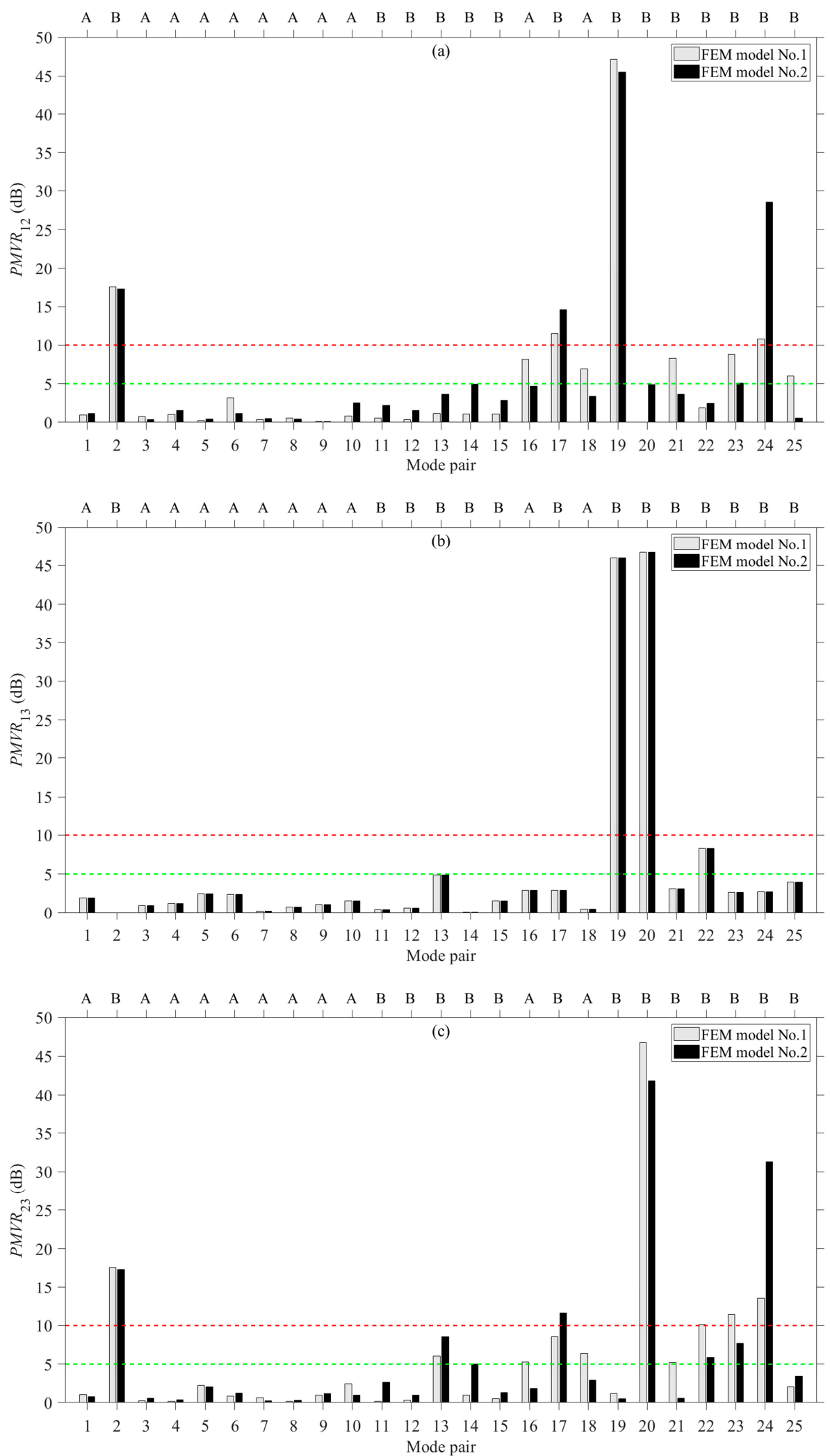

Figure 13. PMVR values for FEM models No.1 and 2 of Beam 2: (a) PMVR12; (b) PMVR13; (c) PMVR23. Mode type A or B for each mode pair is indicated on the upper x-axis. 


\subsection{Sensitivity Analysis for FEM Model No.2}

Assessment of both eigenfrequencies and mode shapes indicates that FEM model No.2 is an improvement on No.1. However, the use of an average $c_{\mathrm{f}}$ value in model No.2 requires further consideration through comparison with the different combinations of $c_{\mathrm{f}}$, as indicated in Table 3. This sensitivity analysis is carried out by focusing on the eigenfrequencies where the differences between the two FEM models were more marked.

Figure 14a,b allows comparison of FEM and experimental eigenfrequencies for Beam 1 and Beam 2, respectively. Results are shown for FEM model No.2 with the three combinations of $c_{\mathrm{f}}$ values. For Beam 1 in the low-frequency range (i.e., mode pairs 1 to 5 ), 60\% of the differences are lower with combination B compared to combinations $\mathrm{A}$ and $\mathrm{C}$. For Beam 2 in the low-frequency range (i.e., mode pairs 1 to 8 ), $62.5 \%$ of the differences are lower with combination A compared to combinations B and C. In the high frequency range (i.e., above the fifth and eighth modes, respectively), the different combinations for the coefficient, $c_{\mathrm{f}}$, tend to have negligible effect on the eigenfrequencies for both beams.
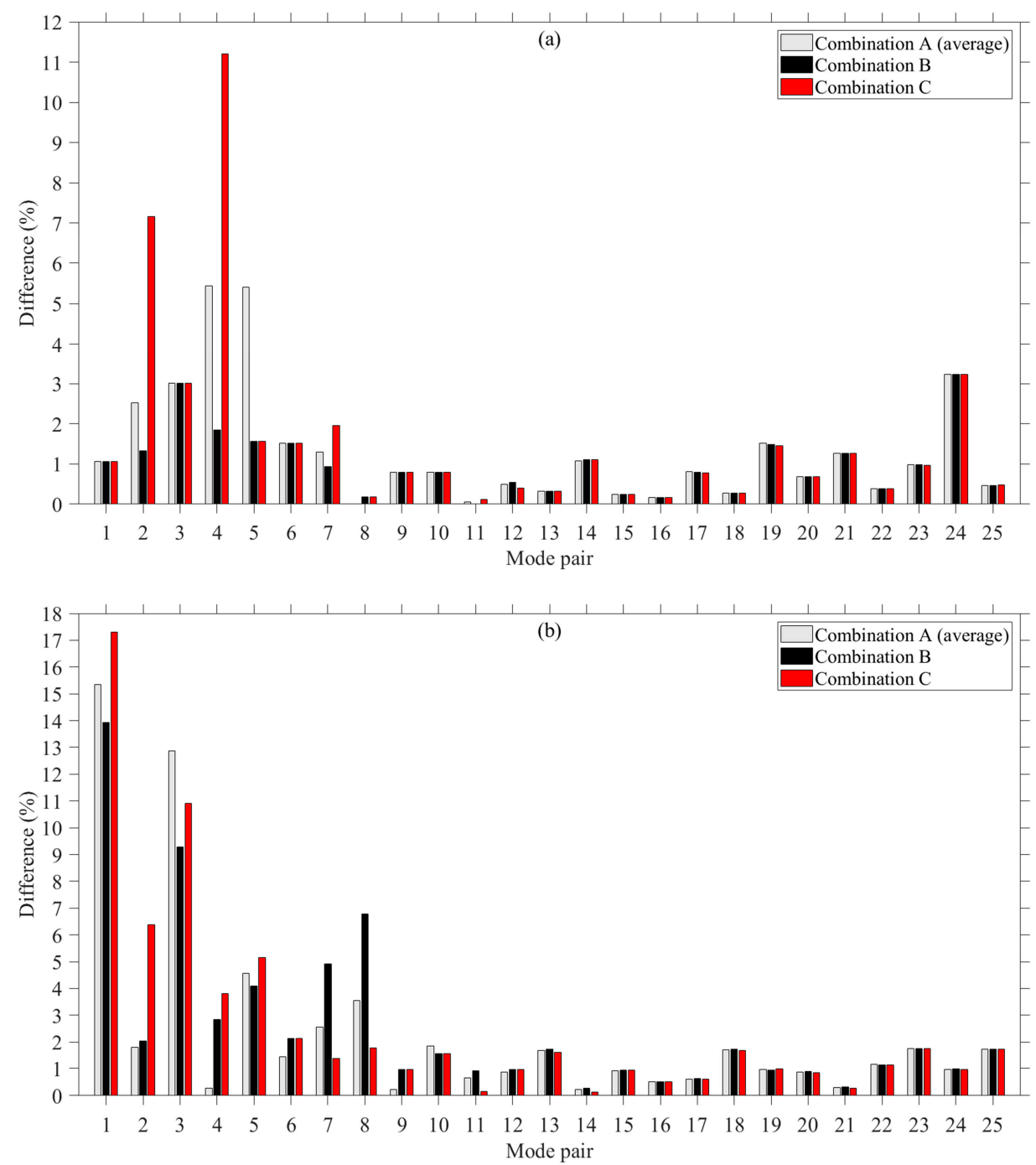

Figure 14. Difference between FEM and experimental eigenfrequencies for FEM model No.2: (a) Beam 1 ; (b) Beam 2.

\section{Conclusions}

FEM models have been developed and compared with the results of experimental modal analysis for two reinforced concrete beams that have discontinuities in the concrete that form dowel-type joints. The models were experimentally validated in terms of 
eigenfrequencies and mode shapes. It was shown that the different modelling methods of the exposed steel bars at the discontinuities mainly affected the eigenfrequencies rather than the mode shapes of the beams. Using springs instead of beam elements improved the agreement in the eigenfrequencies and provided more accurate representation of the response on all parts of the beams. For concrete beams with more than one discontinuity it was shown that MAC is not adequate to assess the validity of the FEM models as this led to misleading results due to the sensitivity of MAC to the large values in the modal vector. PVMR was successfully used to overcome this shortcoming of MAC.

Future work could investigate beams where the steel reinforcement has been bent or damaged along with different damage patterns in the concrete. In addition, similar beams with different discontinuity widths could be measured to verify the spring stiffness formulae.

Author Contributions: Conceptualization, C.H.; methodology, M.F. and C.H.; software, M.F.; formal analysis, M.F. and C.H.; investigation, M.F.; resources, C.H.; writing—original draft preparation, M.F. and C.H.; visualization, M.F.; supervision, C.H.; project administration, C.H.; funding acquisition, C.H. Both authors have read and agreed to the published version of the manuscript.

Funding: This research was funded by the EPSRC and ESRC Centre for Doctoral Training in Quantification Management of Risk \& Uncertainty in Complex Systems and Environments at the University of Liverpool, grant number 1521238.

Acknowledgments: The authors are very grateful to Gary Seiffert (Acoustics Research Unit) for all his help with the experimental set-ups.

Conflicts of Interest: The authors declare no conflict of interest.

\section{References}

1. Bartels, S.A.; Van Rooyen, M.J. Medical complications associated with earthquakes. Lancet 2012, 379, 748-757. [CrossRef]

2. Rom, A.; Kelman, I. Search without rescue? Evaluating the international search and rescue response to earthquake disasters. BMG Glob. Health 2020, 5, 002398.

3. Cogurcu, M.T. Construction and design defects in the residential buildings and observed earthquake damage types in Turkey. Nat. Hazards Earth Syst. Sci. 2015, 15, 931-945. [CrossRef]

4. Ates, S.; Kahya, V.; Yurdakul, M.; Adanur, S. Damages on reinforced concrete buildings due to consecutive earthquakes in Van. Soil Dyn. Earthq. Eng. 2013, 53, 109-118. [CrossRef]

5. Kam, W.Y.; Pampanin, S.; Elwood, K. Seismic performance of reinforced concrete buildings in the 22 February Christchurch (Lyttelton) earthquake. Bull. N. Z. Soc. Earthq. Eng. 2011, 44, 239-278. [CrossRef]

6. Huo, R.; Agapiou, A.; Bocos-Bintintant, V.; Brown, L.J.; Burns, C.; Creaser, C.S.; Devenport, N.A.; Gao-Lau, B.; Guallar-Hoyas, C.; Hildebrand, L.; et al. The trapped human experiment. J. Breath Res. 2011, 5, 046006. [CrossRef] [PubMed]

7. Friedman, M.; Haddad, Y.; Blekhman, A. ACOUFIND: Acoustic Ad-Hoc Network System for Trapped Person Detection. In Proceedings of the IEEE International Conference on Microwaves, Communications, Antennas and Electronic Systems, Tel Aviv, Israel, 2-4 November 2015.

8. Bäckström, C.J.; Christofferson, N. Urban Search and Rescue-An Evaluation of Technical Search Equipment and Methods. Master's Thesis, Lund University, Lund, Sverige, 2006.

9. Filippoupolitis, M.; Hopkins, C. Experimental validation of finite element models representing stacked concrete beams with unbonded surface contacts. Eng. Struct. 2021, 227, 111421. [CrossRef]

10. He, X.G.; Kwan, A.K.H. Modelling dowel action of reinforcement bars for finite element analysis of concrete structures. Comput. Struct. 2001, 79, 595-604. [CrossRef]

11. Kwan, A.K.H.; Ng, P.L. Modelling dowel action of discrete reinforcing bars for finite element analysis of concrete structures. Comput. Concr. 2013, 12, 19-36. [CrossRef]

12. Chung, W.; Kwon, K.; Jang, S.Y. Deflection-based load transfer efficiency of floating slab track. KSCE J. Civ. Eng. 2014, 18, 616-624. [CrossRef]

13. Figueira, D.; Sousa, C.; Neves, A.S. Winkler spring behavior in FE analyses of dowel action in statically loaded RC cracks. Comput. Concr. 2018, 21, 593-605.

14. Xu, B.; Gong, X. Damage detection of reinforced concrete columns based on vibration tests. In Proceedings of the 12th International Conference on Earth and Space 2010: Engineering, Science, Construction, and Operations in Challenging Environments, Honolulu, HI, USA, 14-17 March 2010.

15. Jaishi, B.; Ren, W.X. Damage detection by finite element model updating using modal flexibility residual. J. Sound Vib. 2006, 290, 369-387. [CrossRef] 
16. Pešić, N.; Živanović, S.; Dennis, J.; Hargreaves, J. Experimental and finite element dynamic analysis of incrementally loaded reinforced concrete structures. Eng. Struct. 2015, 103, 15-27. [CrossRef]

17. Earij, A.; Alfano, G.; Cashell, K.; Zhou, X. Nonlinear three-dimensional finite-element modelling of reinforced-concrete beams: Computational challenges and experimental validation. Eng. Fail. Anal. 2017, 82, 92-115. [CrossRef]

18. Ožbolt, J.; Sharma, A. Numerical simulation of reinforced concrete beams with different shear reinforcements under dynamic impact loads. Int. J. Impact Eng. 2011, 38, 940-950. [CrossRef]

19. Tahenni, T.; Bouziardi, F.; Boulekbache, B.; Amziane, S. Experimental and nonlinear finite element analysis of shear behaviour of reinforced concrete beams. Structures 2021, 29, 1582-1596. [CrossRef]

20. Hutton, D.V. Fundamentals of Finite Element Analysis, 1st ed.; McGraw-Hill: New York, NY, USA, 2004.

21. Bamforth, P.; Chisholm, J.; Gibbs, J.; Harrison, T. Properties of Concrete for Use in Eurocode 2; The Concrete Centre: Surrey, UK, 2008; ISBN 978-1-904482-39-0.

22. Mosley, B.; Bungey, J.; Hulse, R. Reinforced Concrete Design to Eurocode 2, 7th ed.; Palgrave Macmillan: Basingstoke, UK, 2012; ISBN 978-0-230-30285-3.

23. Abaqus 6.14 Documentation and User Manual; Dassault Systèmes Simulia Corporation: Providence, RI, USA, 2014.

24. Atalla, N.; Sgard, F. Finite Element and Boundary Methods on Structural Acoustics and Vibration; CRC Press: Boca Raton, FL, USA; Taylor \& Francis Group: Boca Raton, FL, USA, 2015.

25. Porter, M.; Pierson, N. Laboratory evaluation of alternative dowel bars for use in Portland cement concrete pavement construction. Transp. Res. Rec. J. Transp. Res. Board 2007, 2040, 80-87. [CrossRef]

26. Soroushian, P.; Obaseki, K.; Rojas, M.C. Bearing strength and stiffness of concrete under reinforcing bars. ACI Mater. J. 1987, 84, 179-184.

27. Ewins, D.J. Modal Testing: Theory, Practice and Application, 2nd ed.; Research Studies Press Ltd.: Baldock, UK, 2000; ISBN 0-86380-218-4.

28. Allemang, R.J. The modal assurance criterion-Twenty years of use and abuse. Sound Vib. 2003, 37, 14-21. 